\title{
Visualizations: From complex analyses to actionable findings
}

\author{
Laura G. Militello, Drew M. Bowers, \\ Thomas R. Boehnlein, Robert B. Olding \\ University of Dayton Research Institute \\ laura.militello@udri.udayton.edu
}

\author{
Keith Ambrose \\ KLSS \\ keith.ambrose@kelleylog.com
}

\begin{abstract}
Motivation - To provide visualizations that will support high-level decision makers in leveraging findings from analyses conducted using modeling \& simulation techniques. Research approach Cognitive systems engineering methods were used to examine the decision making process as it exists today, as well as identify goals, challenges and information needs at different phases. Research limitations/Implications - This is ongoing work. The strengths and limitations of the design concepts have not yet been assessed experimentally. Originality/Value - The design concepts resulting from this research have the potential to increase the accessibility of findings from complex multivariate analyses. Presenting results from modeling and simulation analyses in the form of actionable findings will likely increase the value of these powerful analytic tools. Take away message - A key challenge to realizing the potential value of sophisticated modeling \& simulation techniques is in creating effective visualizations for communicating complex multivariate relationships. Simple, familiar visualizations may be the most effective.
\end{abstract}

Keywords

Modeling \& simulation, visualization, complex data sets, decision aiding, collaborative decision making

\section{INTRODUCTION}

Advanced modeling and simulation tools allow for sophisticated projection of future capabilities for a range of technologies. Commonly referred to as Quantitative Technology Assessment (QTA), the U.S. Air Force utilizes these complex analyses to inform funding decisions for future research and development. Anecdotal evidence, however, suggests that moving from the output of QTA analysis to decisions is not always straightforward. This challenge can be characterized as one of transitioning from large, complex data sets - to information - to knowledge - to decisions.

The research team was asked to explore the use of innovative visualization strategies for facilitating communication between analysts and decision makers. This poster describes a user analysis conducted using Cognitive Systems Engineering methods. Key findings from the user analysis drive the conceptual design of a Virtual Design Toolkit incorporating decision support capabilities, as well as templates for creating effective visualizations.

\section{METHODS}

Cognitive Systems Engineering methods (Hollnagel \& Woods, 2005; Rasmussen, Pejterson, \& Goodstein, 1994) were used to explore the cognitive challenges associated with moving from data - to information - to knowledge - to decisions in the context of QTA. The team conducted interviews with three user groups including analysts, technical decision makers, and policy makers. Document analysis was conducted on reports and presentations from previous QTA projects. Documents were examined for specific examples of QTA project objectives, methods, findings, and the visualizations used to communicate these components of each project.

Interview notes and document summaries were analyzed using standard qualitative data analysis techniques associated with cognitive task analysis (Hoffman \& Militello, 2008). A team of three researchers identified key decisions vai examination of interview notes and document summaries. Consensus regarding key decisions was reached. Researchers then re-examined the data to extract information needs associated with each key challenge. In addition, researchers identified where in the QTA process specific decisions were likely to be made, which role (i.e., analysis, technical decision maker, policy maker) was most likely to make the decision, and whether others provided input or guidance.

\section{FINDINGS AND RECOMMENDATIONS}

Table 1 presents a subset of summary findings described in terms of key decisions, information needs and decision owners. In addition, recommended support solutions for each key decision is included in the rightmost column. These key decisions served as a framework for the design of the Virtual Design Toolkit. Design seeds illustrating strategies for supporting each of these cognitive challenges will be included in the poster, as well as a live demonstration of an alpha version of the software. 
Table 1. Summary Findings and Recommendations..

In the Decision Owner column, $\mathrm{A}=$ Analyst, $\mathrm{T}=$ Technical Decision Maker, $\mathrm{P}=$ Policy Maker.

A capital $\mathrm{X}$ indicates decision owner. A lower case $\mathrm{x}$ indicates input provider

\begin{tabular}{|c|c|c|c|c|}
\hline \multirow[t]{2}{*}{$\begin{array}{c}\text { Decision/ } \\
\text { Information Needs }\end{array}$} & \multicolumn{3}{|c|}{$\begin{array}{l}\text { Decision } \\
\text { Owner }\end{array}$} & \multirow[t]{2}{*}{ Decision Support Solutions } \\
\hline & $\mathbf{A}$ & $\mathbf{T}$ & $\mathbf{P}$ & \\
\hline $\begin{array}{l}\text { Manage large data sets } \\
\text { - What data is available } \\
\text { - Where data is stored } \\
\text { - When data was created } \\
\text { - Who created data } \\
\text { - Which project data relates to }\end{array}$ & $\bar{X}$ & & & $\begin{array}{l}\text { A data management tool that eliminates the need to move } \\
\text { up and down folder structures. Navigation via a zoomable } \\
\text { usable interface allows for panning, zooming, and sorting } \\
\text { within a non-hierarchical workspace. This interface will } \\
\text { allow users to quickly sort and find files based on } \\
\text { individual schemas. }\end{array}$ \\
\hline $\begin{array}{l}\text { Visualize findings } \\
\text { - Analytic findings } \\
\text { - Implications for Air Force } \\
\text { level goals }\end{array}$ & $\mathbf{X}$ & $\mathbf{X}$ & & $\begin{array}{l}\text { - A visualization library with templates for highly effective } \\
\text { visualizations. } \\
\text { - A means to create simple animations to illustrate key } \\
\text { points and concepts. }\end{array}$ \\
\hline $\begin{array}{l}\text { Facilitate collaboration across } \\
\text { levels } \\
\text { - Knowledge of others' roles } \\
\text { and information needs } \\
\text { - High level project goals } \\
\text { - Specific analyses/findings and } \\
\text { how they were generated }\end{array}$ & $\mathbf{X}$ & $\mathbf{X}$ & $\mathrm{x}$ & $\begin{array}{l}\text { A stand-alone mode for use by analysts in creating a } \\
\text { briefing that tells a story. } \\
\text { - A collaborative mode for use by analysts and technical } \\
\text { decision makers to frame the problem. } \\
\text { Heuristics to aid the creator of slides in gauging the } \\
\text { complexity of their presentation. These heuristics will } \\
\text { help the user to appropriately tailor the slides to a specific } \\
\text { audience. }\end{array}$ \\
\hline $\begin{array}{l}\text { Funding Decisions } \\
\text { - Credible presenter } \\
\text { - Small set of candidate } \\
\text { - solutions } \\
\text { - Rankings on high-level criteria } \\
\text { - Implications for AF goals } \\
\end{array}$ & $\mathrm{x}$ & $\bar{x}$ & $\mathbf{X}$ & - All of the above \\
\hline
\end{tabular}

\section{CONCLUSIONS}

The Virtual Design Toolkit is proposed as a tool to support the transition from data - to information - to knowledge - to decisions in the context of QTA. The Virtual Design Toolkit facilitates collaborative decision making across a generally serial process in which individuals make decisions and pass them on to the next level. By reframing this as a collaborative decision making process, increasing an awareness of roles other than one's own, and providing tools to support increased communication and sharing of key information, we anticipate that the US Air Force will be able to better leverage findings from complex modeling and simulation analysis. As the Virtual Design Toolkit software development continues, researchers will use the prototype as a test platform to refine collaborative decision making within the QTA process, and seek opportunities to leverage this collaborative environment for other complex analysis and decision making tasks.

\section{ACKNOWLEDGMENTS}

This work was completed under contract \# SA0601188/EEC-0214478 and was sponsored by the Air Force Research Laboratory, Air Vehicles (AFRL/RBAA). We would like to thank David Brown of AFRL for his support and guidance throughout this project.

\section{REFERENCES}

Hoffman, R.R. and Militello, L.G. (2008). Perspectives on Cognitive Task Analysis: Historical origins and modern communities of practice. New York: Erlbaum

Hollnagel E., and Woods, D.D. (2005). Joint Cognitive Systems: Foundations of Cognitive Systems Engineering. Boca Raton, FL: Taylor and Francis.

Rasmussen, J., Pejterson, A.M., Goodstein, P.E. (1994). Cognitive Systems Engineering. New York: Wiley. 